\title{
NOVOS DADOS ACERCA DOS DEPÓSITOS AURÍFEROS ASSOCIADOS A VEIOS DE QUARTZO, E A DEGRADAÇÃO AMBIENTAL NA PORÇÃO SUDOESTE DO MUNICÍPIO DE CUIABÁ - ESTADO DE MATO GROSSO, BRASIL
}

Deocleciano BITTENCOURT ROSA (1)

Ricardo Kalikowski WESKA (2)

Jean Pierre GAUTHIER (3)

Shasikante RANTSORDAS (4)

Jean Claude SAMAMA (5)

(1) - Universidade Federal de Mato Grosso - Departamento de Geografia. NUPGEO Núcleo de Pesquisas Geográficas. Av. Fernando Correa da Costa S/N. Cidade Universitária - Coxipó. 78.060-900 Cuiabá - Mato Grosso - Brasil.

(2) - Universidade Federal de Mato Grosso - Departamento de Recursos Minerais. Av. Fernando Correa da Costa S/N. Cidade Universitária - Coxipó. 78.060-900 Cuiabá Mato Grosso - Brasil.

(3) (4) - Université Claude Bernard - Lyon 1 - Institut Universitaire de Technologie B. 17, Rue de France. 69627 - Villeurbanne Cédex - France.

(5) - Institut National Polytechnique de Lorraine - École Nationale Supérieure de Géologie de Nancy. Avenue de la Forêt de Haye - 54.500 Vandoeuvre Lès Nancy - France.

\begin{abstract}
In the South-West portion of the Cuiabá Muncipality is situated the homonymous city, capital of Mato Grosso State, in Center-West Region of Brazil, which Center-North sector, at the urban and peri-urban zones are common auriferous deposits grooved in the degree metamorphic rocks belonging to lithostatigraphic unity Cuiabá Group, where the lithotypes predominant locally are phyllites containing intercalations of metasandstones, metasiltstones, metaconglomerates and quartzites.

This metamorphic sequence shows evidences of ruptures and is sectioned by quartz veins in all directions, constituting sometimes real swarms, with aspects of a big "stockwork", which the more profound, more constant they are.

As a rule occur two types of auriferous deposits, that are related to faults and fractures, filles by quartz, carbonates and sulfides, and also to chemical sedimentation referred to supergenic enrichement, that is characterized by occurrence of the extended lateritic plateau and by the placers that exist on the form of elluvial, colluvial, and alluvial deposits.

Locally can be seen many works of gold extraction in the mode of prospection and this search of this mineral goods bas been done for a long time by prospectors and by the people that live in this area of Cuiabá, however at the most rudimentary and randomly way, that caused in certain sites the deposits exhaustion, where the excavations achieved for the withdraw of material which is washed for the gold obtainment, are abandoned and the
\end{abstract}


erosive process actuation locally, provoke the formation of true craters, which come itself accumulating and creating one desolating feature of environmental degradation, and the that is curious, which after any heavy rainfall, the people profit the remains material accumulation for wash and obtain some gold.

Some privates firms settled themselves locally, and with the execution of more reliable search and prospection works, they discovered deposits on the form of lode, that presented more yield for them.

The gold extracted form local deposits is generally granulated, or in small flakes or small nuggets.

\section{RESUMO}

Na porção Sudoeste do Município de Cuiabá, está situada a cidade Homônima, capital do Estado de Mato Grosso, onde em seu setor Centro-Norte, nas faixas urbana e periurbana, são comuns depósitos auríferos encaixados nos metamorfitos de baixo grau pertencentes ao Grupo Cuiabá, onde os litotipos predominantes localmente, são filitos contendo intercalações de metarenitos, metasiltitos, metaconglomerados e quartzitos.

Esta seqüência metamórfica exibe evidências de cizalhamentos, e é seccionada por veios de quartzo em todas as direções, que constituem, por vezes, verdadeiros enxames, com aspectos de um grande stockwork, que quanto mais profundos, mais constantes são.

Geralmente ocorrem dois tipos de depósitos auríferos, que estão relacionados a falhamentos e fraturamentos, preenchidos por quartzo, carbonato, sulfetos, e também a sedimentação química, referida ao enriquecimento supergênico, que está caracterizado pela ocorrência de platôs lateríticos alongados e pelos plácers que existem na forma de depósitos eluvionares, coluvionares e aluvionares.

Localmente podemos notar diversos trabalhos de extração do ouro na forma de garimpagem, e esta busca é realizada há muito tempo pelos garimpeiros e pela população que habita esta área de Cuiabá, todavia da maneira mais rudimentar e aleatoriamente, o que provoca em certos sítios a exaustão dos depósitos, onde as escavações abandonadas, estão expostas a ação de processos erosivos, o que vem ocasionando a degradação ambiental, que poderá se tornar irreversível.

Algumas empresas privadas se instalaram localmente, e com execução de trabalhos de prospecção e pesquisa mais seguros descobriram depósitos filoneanos, que apresentam maior rentabilidade para as mesmas.

O ouro extraído dos depósitos locais é geralmente granulado, ou então em pequenas fagulhas e pequenas pepitas.

\section{1 - INTRODUÇÃO}

\section{1 - Aspectos Gerais}

O Município de Cuiabá, quase todo situado na região conhecida como Baixada Cuiabana (Almeida 1964), caracteriza-se por apresentar depósitos auríferos e outros minerais associados a veios de quartzo, numa área de aproximadamente $200 \mathrm{~km}^{2}$, entretanto no setor Sudoeste do mesmo estes depósitos são mais expressivos, e estão localizados na porção Centro-Norte a Nordeste da cidade de Cuiabá e circunvizinhanças, se constituindo, 
por vezes, numa opção de trabalho para garimpeiros e pela população local.

\section{2 - Localização e Acesso}

A área de estudos está localizada na porção Centro-Sul do Estado de Mato Grosso, e tal como vimos anteriormente nos setores Centro-Norte a Nordeste da Cidade de Cuiabá (Figura 1).

O acesso a esta área é possibilitado através das rodovias federais BR'S-070, 163 e 364. A Rodovia Federal BR-070, tem seu início em Brasília, e encontra as Rodovias BR163 e BR-364 no trevo da Serra de São Vicente em Mato Grosso, e depois atingem a Cidade de Cuiabá.

De Cuiabá parte a Rodovia Estadual MT-251 (Cuiabá - Chapada dos Guimarães) que delimita a área em apreço no sentido SW - NE, após o entroncamento para o Distrito da Guia, passando pelos Bairros Jardins Ubirajara, Florianópolis, Lagoa Dourada e Vitória. Do Jardim Vitória através do trevo de acesso da MT-251 com a Avenida Historiador Rubens de Mendonça, atingimos o Jardim Novo Paraíso, e em todos estes bairros encontramos as ocorrências dos depósitos auríferos e principalmente, no Jardim Novo Paraíso, onde existe maior facilidade de acesso.

\section{2 - METODOLOGIA}

Inicialmente foi levada a efeito uma pesquisa bibliográfica de cunho geográficogeológico-geomorfológica, para uma melhor contextualização do tema, em face da inexistência de estudos acerca da área em escala de detalhe. Em seguida foram realizados estudos fotointerpretativos em fotografias aéreas verticais pancromáticas, obtidas em 1966 pelo AST-10/USAF-United States Air Force na escala 1: 60.000, e concomitantemente, estudos comparativos nas imagens LANDSAT/TM-07, bandas 3, 4 e 5, publicadas pelo Instituto Nacional de Pesquisas Espaciais (INPE) em 2000, na escala 1:100.000, com os dados transpostos para o mapa índice confeccionado a partir da carta planialtimétrica, Folha de Cuiabá na escala 1:100.000, de índice de nomenclatura SD.21-Z-C-V, editada em 1975 pela DSG - Diretoria de Serviço Geográfico do Ministério do Exército.

$\mathrm{Na}$ determinação das localizações das vias de acesso e toponímias, foi utilizada como base cartográfica o Mapa Político Administrativo e Rodoviário do Estado de Mato Grosso, confeccionado pelo INTERMAT - Instituto de Terras do Mato Grosso em 2002, na escala 1: 1.500 .000 .

Foram utilizadas também nesta fase as cartas temáticas elaboradas pelo Projeto RADAMBRASIL, Folhas SD.21/Cuiabá, na escala 1: 1000.000, de Barros et al (1982), Ross \& Santos (1982), e também por Bittencourt Rosa et al., (1996, 2002).

\section{3 - ASPECTOS FISIOGRÁFICOS}

Regionalmente o condicionamento climático não é uniforme, e podemos caracterizar uma variação sazonal, com duas estações diferenciadas, uma seca e outra chuvosa, o que evidencia um clima tropical a estações contrastadas, ou seja, o de número 2 (dois), segundo a classificação climática de Estienne \& Godard (1970), para as grandes linhas do clima de Durand-Dastès (1968), apresentada por Tardy (1986).

As temperaturas variam entre $28^{\circ}$ a $42^{\circ} \mathrm{C}$ na estação seca, e entre $24^{\circ}$ a $38^{\circ} \mathrm{C}$ na estação chuvosa. A pluviosidade média anual é de $1600 \mathrm{~mm}$. 
No conjunto fitofisionômico predomina o Cerrado (Savana), com presença de Campo Cerrado (Savana Arbórea Aberta), Campo Sujo (Savana Parque), Campo Limpo (Savana Gramino-Lenhosa), Cerradão (Savana Arbórea Densa), Matas (Ciliar e Galeria) e Áreas Desmatadas (Pastagens e Áreas Cultivadas).

Toda esta faixa é drenada pelos Córregos do Jaú, Três Barras, dos Médicos e do Cabral no interflúvio das Bacias Hidrográficas do Ribeirão do Lipa e do Rio Coxipó, afluentes do Rio Cuiabá.

Os solos predominantes nesta área são dos tipos: Latossolos, Neossolos Litólicos e Regolíticos, Cambissolos, Organossolos e Lixossolos (Embrapa, 1998 e Bittencourt Rosa et al., 2002).

O relevo é do tipo parcialmente ondulado a ondulado, correspondendo aos altos e baixos topográficos da Baixada Cuiabana, com as altitudes oscilando entre 170 a 200 metros.

\section{4 - ASPECTOS GEOLÓGICOS}

A área em foco está constituída geologicamente por metamorfitos de baixo grau pertencentes ao Grupo Cuiabá de idade referida ao Pré-Cambriano Superior compreendendo filitos com intercalações de metarenitos, metassiltitos, metaconglomerados e quartzitos (Figura 2); Coberturas Detrito - Lateríticas do Terciário e Aluviões Recentes.

Toda esta seqüência está intensamente dobrada (Figura 3), sendo seccionada por veios quartzosos geralmente descritos por duas gerações, com a mais antiga sendo concordante com as principais foliações, e uma mais recente que preenche fraturas que estão orientadas perpendicularmente à direção geral de estruturas do Grupo Cuiabá, N20 $50^{\circ} \mathrm{E}$.

A Unidade Cobertura Detrito - Laterítica está sobreposta em discordância erosiva, recobrindo as rochas do Grupo Cuiabá. As espessuras podem variar de 0,5 a 2,5 metros, estando constituída por detritos eluvionares, coluvionares e aluvionares, com estes últimos sendo relacionados às redes hidrográficas do Ribeirão do Lipa e do Rio Coxipó e seus afluentes que drenam a área em questão. Essas aluviões se constituem por uma matriz areno-argilosa fina a grossa, mal classificada, que engloba geralmente fragmentos, cascalhos e seixos de quartzo, filitos, metarenitos e quartzitos.

A espessura destas aluviões podem atingir, às vezes 8 (oito) metros, e as mais extensas regionalmente pertencem ao Ribeirão do Lipa.

Alguns estudiosos desde o início do século passado, até os dias atuais, os que mais contribuíram com publicações recentes acerca das mineralizações auríferas associadas aos veios de quartzo, entre eles: Colturato et al., (1989), Weska et al., (1990), Bittencourt Rosa et al., (1992) e Bittencourt Rosa et al., (2003), asseguram diversas direções para estes veios de quartzo, que constituem verdadeiros enxames (Figura 4), às vezes se assemelhando a gigantescos stockworks. Del Rey Silva (1990), considera que o ouro na região da Baixada Cuiabana ocorre em teores médios que são menores do que $5 \mathrm{ppm}$, mas que podem atingir centenas de ppm nos veios quartzosos.

\section{5 - RESULTADOS OBTIDOS}

A área de estudos está caracterizada por apresentar mineralizações de ouro e 
também de sulfetos e materiais de construção.

Dois tipos de depósitos auríferos puderam ser reconhecidos regionalmente, ou sejam: depósitos lateríticos e depósitos filoneanos.

\section{1 - Depósito Laterítico}

Este depósito é formado pela precipitação química dos óxidos de ferro e normalmente, se apresentam na forma de extensos platôs pouco espessos. O ouro ocorre concentrado sob a forma de grãos, fagulhas e pepitas, ou em bolsões de forma aleatória.

O ouro contido nos depósitos lateríticos foi oriundo da alteração meteórica dos filitos e dos veios de quartzo, a partir da exumação destas rochas nos processos erosivos referidos à Bacia do Pantanal.

Em geral os garimpeiros e a população local procuram este bem mineral nesses depósitos, contudo infortuitamente e principalmente após as chuvas torrenciais.

\section{2 - Depósito Filoneano}

Neste tipo de mineralização o ouro está confinado à falhas, fraturas e fissuras, com atitudes preferenciais NW/NE e NW/SW, descontínuas em profundidade, com larguras variando de 30 a $50 \mathrm{~cm}$, que estão preenchidas predominantemente, por quartzo, carbonato, plagioclásio (albita) e sulfetos (pirita e marcassita), apresentando uma zoneação simétrica na forma de "salbandas". Esses depósitos estão relacionados aos filitos, metarenitos, metassiltitos e quartzitos.

Os veios $\mathrm{NE} / \mathrm{SE}$, que ocorrem discordantes com a foliação metamórfica, assim como os concordantes (NE/NW) estão caracterizados como filões estéreis.

A mineração nos depósitos filoneanos está relacionada provavelmente à Reativação Wealdeniana de Almeida (1969), de idade Mesozóica, visto que as fraturas NW/NE e NW/SW podem ter sido geradas durante este episódio tectônico.

Nestas condições as mineralizações auríferas ocorrem da seguinte forma: Durante a fase "rift" foram originadas as fraturas por movimentos distendidos da crosta. Em seguida estas fraturas foram preenchidas por: quartzo, carbonatos, plagioclásio e sulfetos. A associação entre estas soluções quentes (hidrotermais) e as rochas hospedeiras, desenvolveram zonas de alterações laterais às fraturas e falhas (salbandas), que se constituíram nas principais zonas mineralizadas nas rochas locais.

O ouro contido nas rochas foi remobilizado da rocha hospedeira através dos planos de foliação e dos fraturamentos. Todavia aquele contido nas "salbandas" não teve origem somente da remobilização do filito. É provável que o líquido ascendente já continha este ouro.

\section{6 - IMPACTOS AMBIENTAIS}

Os estudos dos diversos fatores que atuam na área em foco, associados diretamente, com os aspectos fisiográficos, geológicos e geomorfológicos são considerados os parâmetros que nos conduziram a elaborar esta parte relacionada aos impactos ambientais, para o estabelecimento de uma planificação eficaz, para a preservação ambiental da mesma. Outros dados estão associados com os gradientes do terreno e as cotas altimétricas, que podem se modificar em razão do posicionamento das rochas que afloram regionalmente.

Quando nos referirmos ao uso da terra, é importante ressaltar as áreas ocupadas 
fisicamente, as áreas agricultáveis, às áreas escalvadas, às áreas de pastagens, e às áreas de empréstimos para retirada de materiais para a construção civil.

A geração de impactos ambientais está relacionada diretamente, a alguns destes aspectos nesta faixa da cidade de Cuiabá.

Partindo-se desta idéia é possível situar como problemas para a área de estudos, principalmente os movimentos de massa, e a atuação dos mais diversos processos erosivos, tais como pluviais, fluviais, laminares, em pedestal, em pináculos e antrópica, e no leito do Ribeirão do Lipa e do Rio Coxipó e seus afluentes, onde a poluição das águas pela prática garimpeira, e os resíduos sólidos deixados pelos banhistas dos fins de semana nos mesmos, nas praias naturais existentes ou nas artificiais, que vão poluir as águas.

Os endereços onde a garimpagem se faz presente se constituem nos maiores focos da degradação ambiental, onde alguns já foram desativados pelo esgotamento deste bem mineral e pelas dificuldades para a obtenção pelas características do terreno. Esta prática nociva ainda continua em alguns setores apesar da fiscalização do IBAMA e da Fundação Estadual do Meio Ambiente (FEMA).

Tomando-se como base os estudos realizados regionalmente, as observações levadas a efeito, entrevistas com os proprietários e com a comunidade residente, foi possível a montagem do seguinte banco de dados:

A) Regionalmente, os trabalhos de agricultura são realizados geralmente, nas encostas dos vales, nos divisores de água, nas áreas mais planas e nas partes baixas, contudo alguns destes locais não são favoráveis para esta prática. É utilizada nestes trabalhos a faixa de organossolos, ao longo das várzeas do Ribeirão do Lipa e do Rio Coxipó e dos Córregos do Jaú, Três Barras, dos Médicos e do Cabral, com o mesmo sendo realizado, às vezes, de maneira inadequada, com o uso de agrotóxicos e fertilizantes, que contaminam e poluem o próprio solo e as águas;

Algumas faixas de onde a vegetação nativa foi retirada, e as encostas com menor declividade, são utilizadas para a formação de pastagens e edificação de áreas para cultivos. B) As antigas e atuais áreas de garimpagem de ouro da área em questão são objetos de estudos e visitas de interessados em conhecer as mesmas, como acontece nos Bairros: Jardins Florianópolis, Vitória e Novo Paraíso, nas margens do Ribeirão do Lipa e do Córrego do Jaú, onde existe em alguns locais a manutenção do rejeito, que foi lavado nos equipamentos montados pelos garimpeiros ou então bateado, para a busca do ouro e depois abandonado, com o cascalho e a areia sendo, às vezes, utilizado como material de construção pela população local.

O uso impróprio do solo é uma prática que está associada de uma maneira direta, com o desconhecimento da comunidade, que quer realizar seus cultivos, e via de regra esta ação está referida à população que migrou para este local, através de invasões, grilagens de terrenos, ou então advinda dos mais diversos cantos do país, e sobretudo, das regiões sudeste, sul e nordeste, alguns já possuindo pequena prática, em função de cultivos já realizados nas suas áreas de origem, contudo inadequados para com a realidade que irão encontrar.

Os problemas mais diretos referidos a uma inadequada utilização da terra, associados a uma falta de conhecimento, estão expressos primeiramente, nas construções, em lotes irregulares, em áreas de declive, e também a ausência do tratamento do solo para à agricultura geralmente, sem a realização prévia de um estudo topográfico, onde a edificação 
de curvas de nível nos plantios é importantíssima, assim como a construção de carpas alternadas e de canais para escoamento do fluxo de água em áreas de gradiente acentuado.

Nas porções mais elevadas dos terrenos, os trabalhos agropecuários sem um acompanhamento técnico relativo as microbacias hidrográficas, constitui-se também numa atividade de risco que torna o terreno susceptível a ação de processos erosivos, que podem conduzir à formação de ravinas e voçorocas, que transportam com todo o solo superficial e subsuperficial. A atuação destes processos erosivos pode ser observada em alguns setores da área, sobretudo, durante a estação chuvosa, onde deslizes do manto de decomposição nos terrenos com forte declive são constantes, com transporte de materiais detríticos dos mais diversos, das partes mais altas para as partes mais baixas, quando não assoreando os cursos d'água regionais.

Ao lado das rodovias e em cortes nas mesmas, as áreas ou caixas de empréstimos para retiradas de materiais para a construção civil, as catas abertas para a garimpagem se constituem também em elementos geradores de ravinamentos e voçorocamentos, já que estão sujeitas também, aos mais diversos processos erosivos.

\section{7 - CONSIDERAÇÕES FINAIS}

Os novos dados que foram coligidos para a confecção deste relato trouxeram a baila algumas questões, que evidentemente poderão ser respondidas.

Um fato pode ser a existência ou não de corpos alcalinos intrudidos nos metamorfitos do Grupo Cuiabá regionalmente, que não se encontram ainda expostos em razão da atual ação dos processos erosivos. Estes corpos alcalinos poderiam ter contribuído com suas soluções hidrotermais mineralizantes, para o preenchimento dos sistemas de fraturas NW/NE e NW/SW. Contudo esses sistemas nos depósitos filoneanos devem ter suas gêneses referidas a períodos geológicos distintos, dos que constituíram os sistemas $\mathrm{NE} / \mathrm{SE}$ e $\mathrm{NE} / \mathrm{NW}$, isto porque eles foram preenchidos por soluções de diferentes composições e mostram comportamentos estruturais que avaliam estes pensamentos.

É interessante frisar a presença de concentrações de sulfetos como pirita, marcassita, arsenopirita e galena em amas, mais turmalina, calcita, monazita e quartzo recristalizado em cristais neoformados, geralmente associados ao ouro.

A avaliação de impactos produzidos pela exploração do ouro foi possibilitada a partir das observações efetuadas localmente, seguindo a método dos caminhamentos, e desta forma foi possível distinguir regionalmente sobre o meio natural e biótico os seguintes impactos negativos: desmatamentos e perda da vegetação, modificação na topografia, perda do solo fértil, estragos causados à fauna, assoreamento dos leitos do Ribeirão do Lipa, do Rio Coxipó e do Córrego do Jaú.

No que tange aos impactos, sobre o ambiente humano pudemos distinguir: a poeira, e a poluição sonora.

\section{7 - BIBLIOGRAFIA}

ALMEIDA, F. F. M. de. 1964. Geologia do Centro-Oeste Matogrossense. Boletim da Divisão de Geologia e Mineralogia, Rio de Janeiro, (215): 1 - 133. 
ALMEIDA, F. F. M. de. 1969. Diferenciação Tectônica da Plataforma Brasileira. In: CONGRESSO BRASILEIRO DE GEOLOGIA, 23, Salvador, Bahia, Anais do., pp. 29 46, Sociedade Brasileira de Geologia, Salvador, Bahia.

BITTENCOURT ROSA, D.; WESKA, R. K.; OST, E. M. F. \& OLIVEIRA, M. G. 1992. Uma Contribuição ao Desenvolvimento Operacional de Pesquisa Sistemática sobre as Rochas Pertencentes ao Grupo Cuiabá, Aflorantes nos Municípios de Chapada dos Guimarães, Cuiabá, Paranatinga e Várzea Grande no Estado de Mato Grosso. Relatório Final de Pesquisa, Conselho Nacional de Desenvolvimento Científico e Tecnológico/ Universidade Federal de Mato Grosso, CNPq/UFMT, Processo $n^{\circ} 302380 / 88-4,88$ pp.

BITTENCOURT ROSA, D.; GELA, A.; ALVES, D. de. O.; MACEDO, M.; GARCIA NETTO, L. da. R.; PINTO, S. D. S.; BORGES, C. A.; ROSSETO, O. C.; TOCANTINS, N.; LOPES dos SANTOS, P. \& GERALDO, A. C. H. 2002. Um Estudo Geoambiental Comparativo das Características Morfoestruturais e Morfoesculturais nas Áreas das Bacias do Alto Rio Paraguai e do Rio Teles Pires no Estado de Mato Grosso. Projeto de Pesquisa, Relatório Final, Fundação de Amparo à Pesquisa do Estado de Mato Grosso - FAPEMAT, $319 \mathrm{pp}$.

COLTURATO, S. C. de.; RUIZ, A. V. \& DONEGÁ, J. L. 1989. Contribuição à Geologia das Circunvizinhanças da Mineração Casa de Pedras, Baixada Cuiabana - Mato Grosso. Relatório de Graduação em Geologia, Departamento de Geologia, Instituto de Ciências Exatas e da Terra, Universidade Federal de Mato Grosso, Cuiabá, MT, 60 pp.

DEL REY SILVA, L. A. H. 1990. Ouro no Grupo Cuiabá, Mato Grosso: Controles Estruturais e Implicações Tectônicas. In: CONGRESSO BRASILEIRO DE GEOLOGIA, 36, Natal, RN, Anais do., Volume 6, pp. 2520 - 2525, Sociedade Brasileira de Geologia, Natal, RN.

DURAND-DASTES, F. , 1968 - Climatologie. Encyclopaedia Universalis, 4, pp. 618 $-624$.

ESTIENNE, P \& GODARD, A. , 1970 - Climatologie. Armand Colin, Paris, Colection U, $365 \mathrm{pp}$.

TARDY, Y., 1986 - Le Cycle de L'Eau - Climats, Paléoclimats et Géochimie Globale. Masson Editeurs, Paris, 338 pp.

WESKA, R. K.; BITTENCOURT ROSA, D.; FIGUEIREDO JUNIOR, O. C.; PERIN, A. L. \& COLTURATO, S. C. de. 1990. Características dos Depósitos Auríferos da Mineração Casa de Pedras Ltda, Cuiabá - MT. In: ENCONTRO CIENTÍFICO E DE DESENVOLVIMENTO TECNOLÓGICO DA AMAZÔNIA E CENTRO - OESTE, 1, Cuiabá, MT, Universidade Federal de Mato Grosso, Boletim de Resumos, pp. 33, Cuiabá, MT. 


\section{8 - ANEXOS}

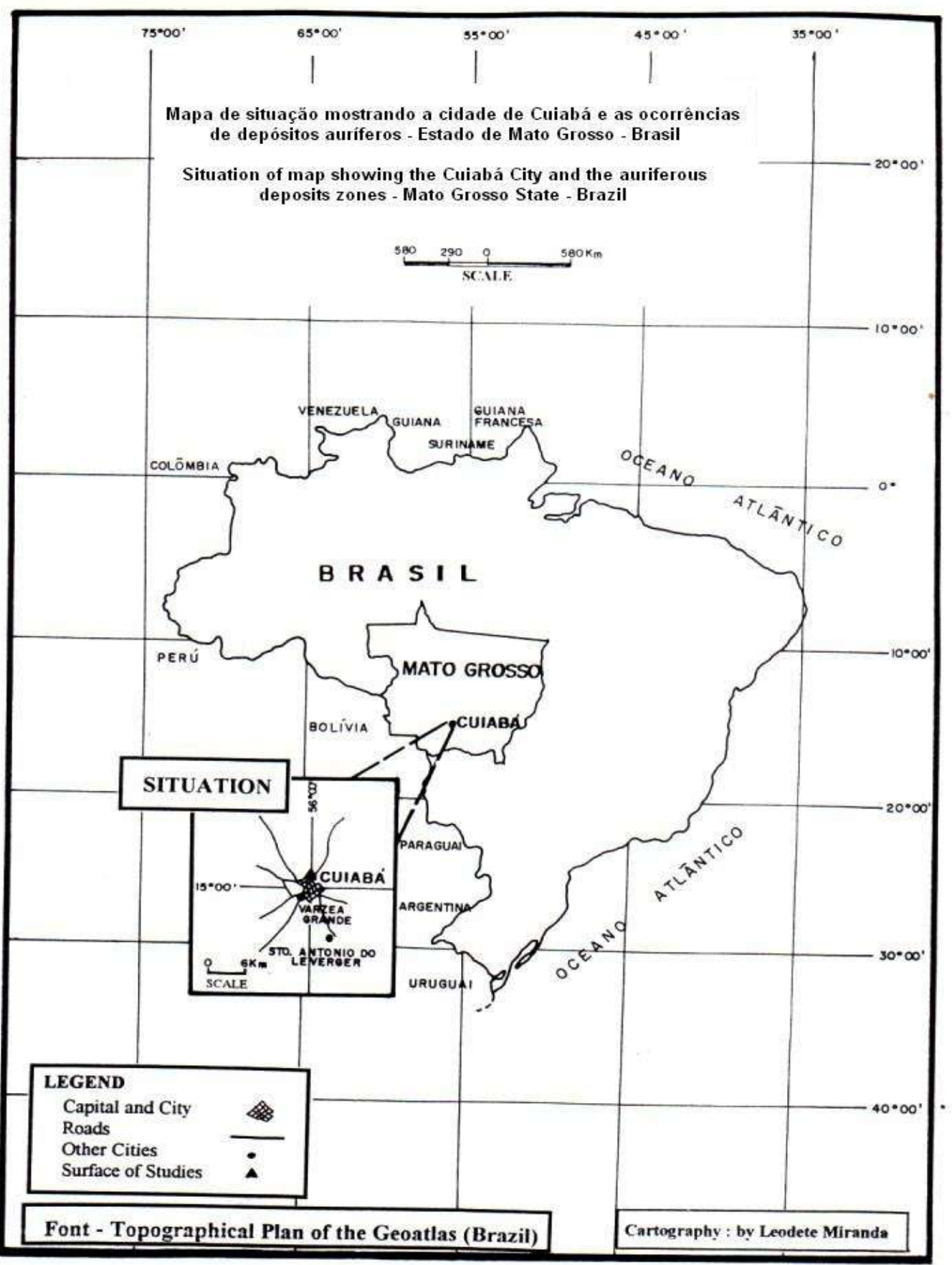

Fig. 1 - Mapa de localização mostrando a cidade de Cuiabá e as áreas de ocorrências dos depósitos auríferos. 
Situation of map showing the Cuiabá City, and the auriferous deposits areas.

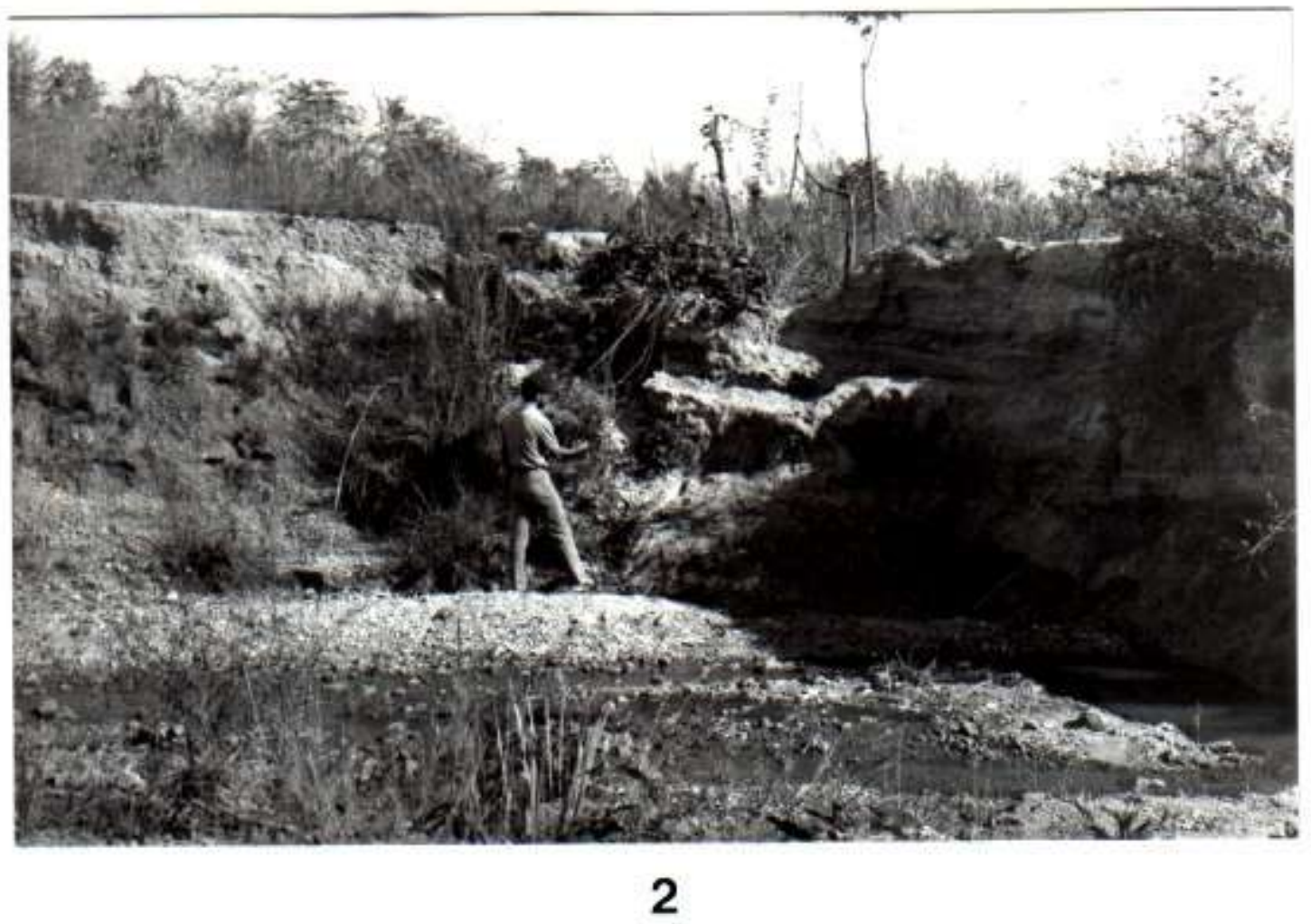

Fig. 2 - Os litotipos predominantes localmente são filitos contendo intercalações de metarenitos, metassiltitos, metaconglomerados e quartzitos.

The lithotypes predominant locally are phyllites containing intercalations of metasandstones, metasiltstones, metaconglomerates and quartzites. 


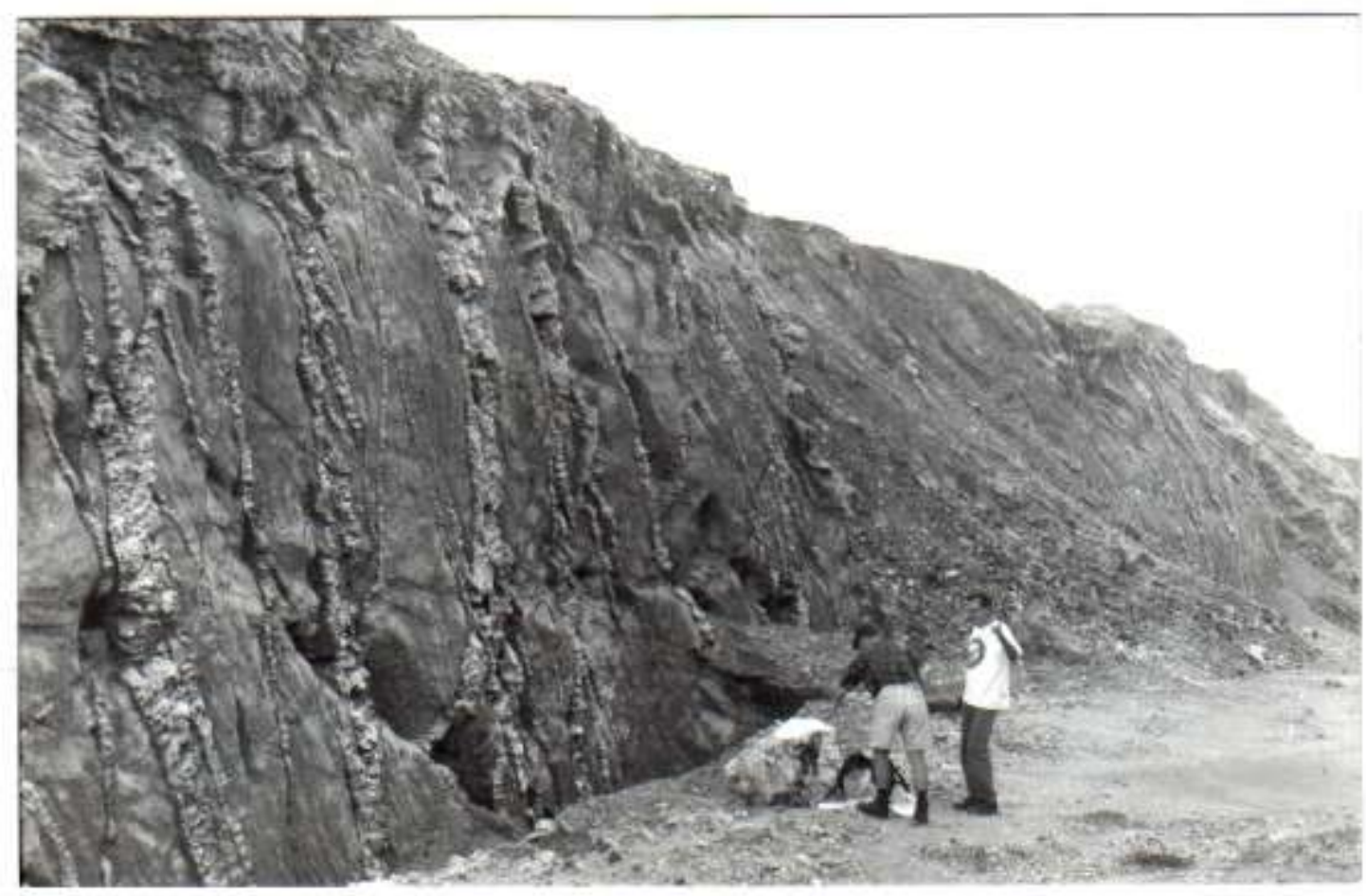

3

Fig. 3 - Filitos dobrados pertencentes ao Grupo Cuiabá aflorantes na margem direita do Córrego do Cabral. Local - Mineração Casa de Pedras, Cuiabá.

Phyllite folded belonging to Cuiabá Group out crop in the right margin of the Cabral brook. Local - Casa de Pedras Mining, Cuiabá. 


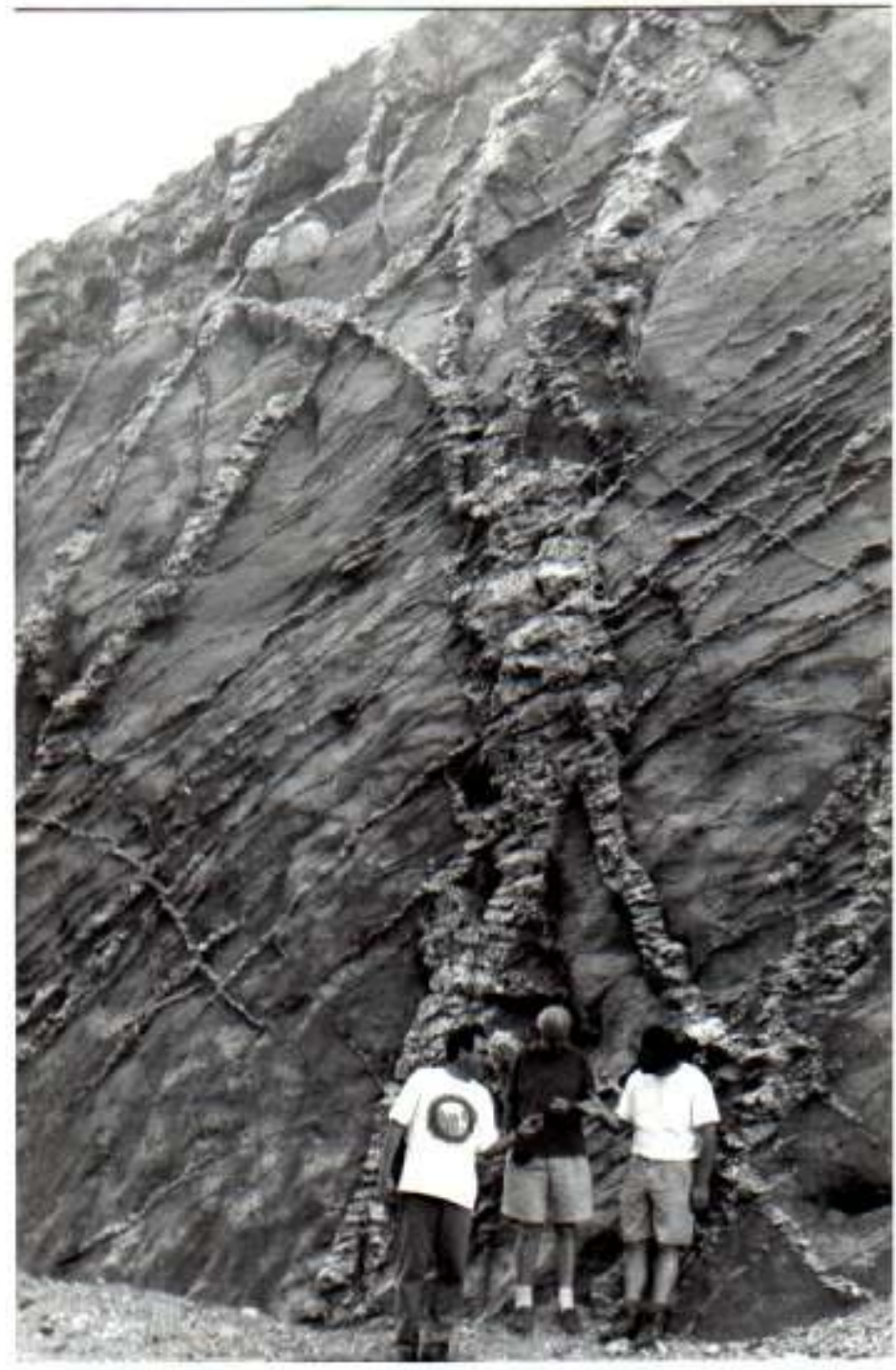

4

Fig. 4 - Disposição dos veios de quartzo em todas as direções, constituindo verdadeiros enxames, com aspectos de um grande "stockwork". Local - Mineração Itapoã, Cuiabá.

Disposition of the quartz veins in all directions, constituting sometimes real swarms, with aspects of a big "stockwork". Local - Itapoã Mining, Cuiabá. 